\title{
Literatura infantil em ação: as marcas da autoria feminina nas obras aprovadas pelo PNLD/Literário
}

\author{
Ana Crelia Penha Dias* \\ Camila Rodrigues Viana**
}

\section{Resumo}

O lugar da mulher nas sociedades nunca esteve tanto em evidência como neste século, embora as discussões não tenham sido inauguradas agora. $\mathrm{O}$ presente trabalho faz um percurso de análise da representatividade de autoria feminina nas políticas públicas voltadas para o livro literário, especialmente em torno dos livros aprovados pelos Plano Nacional de Materiais e Livro Didático (PNLD) literários, do edital do ano de 2018. Com efeito, tecemos um diálogo entre a literatura infantil, a presença e a legitimação da autoria feminina, em uma historiografia com marcas de jogo simbólico e forças de gênero. Delineamos um caminho que buscou tanto quantificar as obras de autoria feminina como problematizar os critérios avaliativos do PNLD e a recorrência e a predominância de algumas obras. Assim, notamos que a luta pelo lugar nas produções artísticas literárias ainda é progressiva e lenta, mas os resultados são expressivos e marcados na história.

Palavras-chave: Literatura infantil. Autoria feminina. PNLD. Livro literário.
* Cursou graduação em Letras pela Universidade do Estado do Rio de Janeiro (1994), especialização em literatura infantil e juvenil (1999), mestrado (2003) e doutorado (2008) em Letras (Letras Vernáculas) pela Universidade Federal do Rio de Janeiro. Atualmente é professora da Universidade Federal do Rio de Janeiro. Tem experiência na área de Letras, com ênfase em Literatura Brasileira, atuando principalmente nos seguintes temas: literatura infantil, literatura brasileira, literatura e ensino e formação do leitor literário. É membro integrante do Grupo de Pesquisa Encontros com a Literatura Infantil/Juvenil: ficção, teorias e práticas, coordenado pela profa. dra. Regina Michelli (UERJ). É líder do grupo de pesquisa Literatura e Educação literária (dgp.cnpq.br/dgp/espelhogrupo/5906903233650588) e coordenadora do GT da Anpoll Literatura e Ensino. E-mail: anacrelia@gmail.com

** Doutoranda em Letras: Ensino de Línguas e Literatura na Universidade Federal do Tocantins (UFT). Mestra em Letras (2015). Especialista em Gestão, Supervisão e Orientação Educacional (2014). Graduada em Pedagogia pela Universidade Federal do Maranhão (UFMA) (2013) e em Letras: Língua Portuguesa e Inglesa e respectivas literaturas pela Universidade Estadual do Maranhão (UEMA) (2014). Docente da UFMA, do Curso de Comunicação Social/Jornalismo e Pedagogia, Campus Imperatriz. Colaboradora do PROFEBPAR/ PAFOR-UFMA. Tem experiência profissional nas áreas de Comunicação (Jornalismo), Educação (Pedagogia e Letras) e Saúde (Medicina e Enfermagem). Atuação nas áreas de discurso, análise de livro e material didático, práticas de alfabetização e letramento e políticas públicas da educação (PNLD, BNCC e DCTMA). E-mail: teachercamilars@gmail.com

Data de submissão: abril de 2020 - Data de aceite: julho de 2020 http://dx.doi.org/10.5335/rdes.v16i2.10879 


\section{Palavras iniciais}

Discussões sobre autoria feminina têm sido mais frequentes e parecem encaminhar hoje uma construção epistemológica que se autoriza autonomia crítica e teórica em relação ao percurso da literatura hegemonicamente legitimada. A representatividade das mulheres na literatura dita geral, entretanto, ainda avança com menos vigor do que a de autoras que escrevem para o público infantil e, por vezes, também juvenil. Entretanto, se há presença mais efetiva de mulheres na escrita para crianças, tal fator se deve a uma histórica relação do feminino com o cuidado, a educação e a formação leitora das crianças.

Este trabalho propõe-se a analisar a presença da autoria feminina na seleção do Plano Nacional de Materiais e Livro Didático (PNLD)/literário de 2018 para o público dos anos iniciais do ensino fundamental, a partir de um recorte que busca marcas de recorrência de número de obras; grau de relevância da autora no cenário da produção escrita e da formação de leitores; reconhecimento crítico da autora no cenário da produção para crianças.

Entendendo as seleções governamentais como formas também de legitimação de autores e obras, este trabalho tece reflexões sobre avanços e repetições de padrão no que concerne à formação de certo cânone escolar, na perspectiva do recorte feito e do que representa metonimicamente uma lista de um programa que, na verdade, se sustenta por meio de uma política pública.

\section{Literatura de autoria feminina: silêncio ou protagonismo?}

Ser uma escritora contemporânea é dialogar com a história da inserção das mulheres no campo literário, considerando-se a atuação dos movimentos feministas como força social. A autoria feminina é um gesto de transgressão (LEAL, 2010, p. 183).

Historicamente, as vozes do cânone literário são predominantemente ocidentais, brancas e masculinas, e isso não é mais novidade, assim como não são menos frequentes hoje vozes dissonantes a essa constituição ainda hegemônica. São perceptíveis e já flagrados pela crítica especializada os apagamentos de obras de autoria feminina ao longo das histórias da literatura universais, e o caso brasileiro não é uma exceção a esse fenômeno. Como prova disso, Batista (2011), em seu artigo "A produção literária feminina brasileira nos séculos XVII e XVIII", afirma que autoras como Ângela do Amaral Rangel, Maria Josefa Barreto e Beatriz Francisca de Assis Brandão fizeram parte do rol de autoria da literatura colonial. A autora alega ainda que tanto a historiografia como as 
produções de livros didáticos/literários marginalizaram e/ou excluíram essas mulheres. No que concerne à composição dos materiais didáticos, Batista (2012, p. 804) reforça que

[...] é inaceitável que, em pleno século XXI, nossos alunos saiam da Educação Básica sem o conhecimento dessas que contribuíram para a construção artística e cultural de nossa nação, seja no Período Colonial, seja nas épocas subsequentes.

O que se depreende desse fenômeno excludente das vozes das mulheres, em especial das negras, que chega à escola por meio do recorte do cânone acadêmico, é uma espécie de miniatura em que se sobrelevam ainda questões beletristas em detrimento de uma formação mais representativa de todos os nichos que compõem o tecido social.

De certa forma, podemos afirmar que, em termos de educação literária, assunto a que nos dedicamos, a escola ainda permanece próxima à década de 1960 nos compêndios didáticos do ensino médio, em que, no capítulo dedicado à literatura contemporânea, encontraremos Guimarães Rosa, Clarice Lispector e João Cabral de Mello Neto. Nesse sentido, "o sistema de ensino cumpre inevitavelmente uma função de legitimação cultural ao converter em cultura legítima, exclusivamente através do efeito de dissimulação", ou seja, "ao reproduzir, pela delimitação do que merece ser transmitido e adquirido e do que não me- rece, a distinção entre as obras legítimas e ilegítimas e, ao mesmo tempo, entre a maneira legítima e ilegítima de abordar as obras legítimas" (BOURDIEU, 2007, p. 120). No século XVIII, temos Teresa Margarida da Silva e Orta, autora das Aventuras de Diófanes, podendo ser classificadas como o primeiro romance da literatura brasileira (BATISTA, 2012). De outro lado, temos Maria Firmina dos Reis (1825 - 1917), que também foi considerada a primeira romancista brasileira, autora de um romance abolicionista do país: Úrsula, de 1859 (XAVIER, 2002). Assim,

[...] independentemente de se concordar ou discordar dessa afirmação, fato indiscutível é a ausência da autora na parte mais significativa de nossa historiografia literária (SCHMIDT,1995, p. 56).

Lobo (1992, p. 135), em "A dimensão histórica do feminismo atual”, afirma que:

Ser o outro, o excluso, o estranho é próprio da mulher que quer penetrar no "sério" mundo acadêmico ou literário. Não se pode ignorar que, por motivos mitológicos, antropológicos, sociológicos e históricos, a mulher foi excluída do mundo da escrita só podendo introduzir seu nome na história europeia por assim dizer através de arestas e frestas que conseguiu abrir através de seu aprendizado de ler e escrever em conventos.

Desde muito tempo, as mulheres foram sistematicamente excluídas do universo canônico e, por questões históricas, políticas e sociais, foram ora totalmente silenciadas ora tendo parcialmente acesso à comunidade científica e literária, com 
obras restritas a temas ou não alfabetizadas, preparadas apenas para os deveres domésticos e conjugais. Segundo Virgínia Woolf (1985), o problema começa bem antes, com a exclusão da mulher do mundo das letras e artes. Apesar do silenciamento e apagamento da mulher nas narrativas históricas da produção literária, não temos dúvida de sua participação.

No caso brasileiro, encontramos um estudo de Marisa Lajolo e Regina Zilberman, A formação da leitura no Brasil (2009), sobre a inserção da mulher no universo letrado, que fornece algumas pistas do que significa a subtração histórica da autoria feminina do cânone literário. Se a mulher tem atraso histórico de aparição no cenário literário, isso se deve também ao acesso tardio à escolarização e, por consequência, à leitura. Entretanto, no cenário dos subsistemas literários infantil e juvenil, mais ligados à escolarização, porque pensados com mais clareza no ponto de vista dos destinatários, a presença feminina é mais abundante nos textos presentes nos materiais didáticos. É o que estudaremos a partir de agora.

\section{Literatura infantil: o funcionamento do PNLD/Literário}

O atual Plano Nacional de Materiais e Livro Didático (PNLD), até 2017, era nomeado de Plano Nacional de Livro Didá- tico, reconfigurado pelo Decreto $\mathrm{n}^{0} 9.099$, ao incluir compras de livros literários no escopo dos editais que tradicionalmente só compravam livros didáticos. Essa mudança se deu pela suspensão do Plano Nacional Biblioteca na Escola (PNBE). O PNLD teve início na década de 1980 e apresentou como pretensão principal a melhoria da educação básica, por meio dos processos de avaliação, escolha e distribuição de material didático. Apesar de a implementação ter sido realizada na década de 1980, apenas na década de 1990 a avaliação do livro didático começou a se concretizar e a ser mais criteriosa. Conforme afirma Munakata (1997, p. 593):

A partir de 1996, o Governo Federal, por intermédio de uma equipe formada pelo Ministério da Educação, passou a avaliar os livros didáticos, ao menos aqueles encaminhados pelas editoras. Isso acabaria por constituir um novo grupo de leitores - o dos avaliadores $\square$, reduzidíssimo em número, mas altamente poderoso, na medida em que é capaz de influir sobre a aquisição, pelo governo, de livros didáticos, numa operação comercial que envolve dezenas de milhões de exemplares. Como esse seleto grupo lê o livro didático? Cabe também indagar se as editoras redefiniram - e como - as estratégias para tentar assegurar que seus produtos sejam aprovados por esses leitores.

A fim de deixar claro o modo de funcionamento do PNLD, o Fundo Nacional de Desenvolvimento da Educação (FNDE) ressalta que o programa faz a aquisição e a distribuição das obras para os alunos dos ensinos fundamental e médio do en- 
sino regular ou da Educação de Jovens e Adultos (EJA). Recentemente, em 2018, com a promulgação da Base Nacional Comum Curricular, o plano passou por uma nova reconfiguração, para a inclusão de obras literárias, para remediar a descontinuidade abrupta do PNBE. Por meio do Decreto-Lei $\mathrm{n}^{\circ}$ 1.006, de 30 de dezembro de 1938, os livros de leitura "são os livros usados para leitura dos alunos em aula; tais livros também são chamados de livro-texto, compêndio escolar, livro escolar" (OLIVEIRA, 1980 apud FREITAG; MOTTA; COSTA, 1997, p. 13).

Segundo argumentos de sua implantação controversa, a Base Nacional Comum Curricular (BNCC) teria entre suas finalidades integrar a política nacional da educação básica e contribuir para o alinhamento de outras políticas e ações, nos âmbitos federal, estadual e municipal, referentes a escolhas literárias, formação de professores, avaliação, elaboração de conteúdos educacionais e critérios avaliativos de aprovação e reprovação dos livros didáticos. Entretanto, essa transição de políticas públicas provocou polêmicas em torno do PNLD/ Literário.

Por um lado, a filiação das obras literárias a um programa de livro didático pode ser encarada como forma de acesso à leitura para a turma inteira (no caso do PNBE, as bibliotecas escolares recebiam número de exemplares de uma mesma obra que não permitia o trabalho com o mesmo texto com todos os estudantes de uma mesma turma), visto que a ideia do programa é que o aluno tenha no mínimo dois livros por ano; acrescenta-se que, na maioria dos contextos educacionais, a leitura literária da escola é a única a que o leitor terá acesso (BRASIL, 2018). Entretanto, por outro lado, a associação de obras literárias a programas didáticos, sem um projeto de educação literária em que se invista na educação estética, essas obras estarão voltadas mais especificamente para o uso pedagógico que podem representar no contexto, o que significa ainda um decréscimo na autonomia docente, pois os professores precisam adaptar-se a um conjunto de obras aprovadas pelo programa. A contradição acentua-se mais se pensarmos que quem estabelece critérios e seleciona títulos para o programa são, em sua maioria, professores universitários, e não docentes da educação básica, o que não é uma novidade do PNLD/Literário, pois assim foi também com o PNBE. O desconhecimento da cultura dinâmica de produção, circulação e recepção das obras pode levar a uma seleção plastificada, baseada em críticas já consolidadas, o que é louvável, mas que, encerradas nesse feitio, fecham-se a novas produções. $\mathrm{O}$ volume de publicações nos subsistemas infantil e juvenil ${ }^{1}$ é expressivo e requer crítica contínua para ampliação de referências.

Com a implantação do PNLD/Literário, os livros são escolhidos por meio de 
critérios avaliativos, direcionados para cada disciplina e etapa de ensino, e distribuídos conforme o Quadro 1.

Quadro 1 - Distribuição dos acervos do PNLD/ Literário 2018

\begin{tabular}{|c|c|c|c|}
\hline Categoria & $\begin{array}{l}\text { Acervos } \\
\text { sala de } \\
\text { aula }\end{array}$ & $\begin{array}{l}\text { Acervos } \\
\text { para } \\
\text { biblioteca }\end{array}$ & $\begin{array}{l}\text { Livros } \\
\text { por } \\
\text { aluno }\end{array}$ \\
\hline $\begin{array}{l}1 \text { e } 2-\text { Creche (0 } \\
\text { ano e } 7 \text { meses a } 3 \\
\text { anos e } 11 \text { meses) }\end{array}$ & $\begin{array}{l}20 \\
\text { obras }\end{array}$ & & \\
\hline $\begin{array}{l}3 \text { - Pré-escola (4 } \\
\text { anos a } 5 \text { anos e } \\
11 \text { meses) }\end{array}$ & $\begin{array}{l}25 \\
\text { obras }\end{array}$ & & \\
\hline $\begin{array}{l}4-\text { Anos iniciais - } \\
1^{\circ} \text { ao } 3^{\circ} \text { ano }\end{array}$ & $\begin{array}{c}35 \\
\text { obras }\end{array}$ & & \\
\hline $\begin{array}{l}5 \text { - Anos iniciais - } \\
4^{\circ} \text { e 5 ano }\end{array}$ & & $\begin{array}{c}50 \\
\text { obras }\end{array}$ & $\begin{array}{l}2 \text { por } \\
\text { aluno }\end{array}$ \\
\hline
\end{tabular}

Fonte: Guia PNLD/Literário (BRASIL, 2018).

Tendo como base o Quadro 1, é importante observar que, nas categorias de 1 a 4, os acervos são para toda classe, de uso coletivo, sendo um acervo para cada turma. Apenas a partir do $5^{\circ}$ ano, a categoria 5 , alunos e professores receberão exemplares individuais, dois por aluno, e diferentes da biblioteca. Ou seja, a premissa de que o programa propiciaria leitura integral de uma mesma obra em um trabalho compartilhado não se sustenta até a etapa 4 . Cada escolha deve ser feita a partir de duas opções, de editoras diferentes. Vale destacar que os livros destinados aos alunos e professores são reutilizáveis e devem ser devolvidos no final do ano letivo. Para as categorias 1 e 2, o Guia do PNLD/Literário recomenda obras literárias em que os aspectos imagéticos se relacionem com a cultura escrita. Já para as categorias 3 , 4 e 5 , é orientado que sejam obras que estimulem potencialidades multissemióticas nas diversas formas dos gêneros literários e temas. Norteia-se, ainda, que as escolhas devem ser feitas pelo corpo docente. A avaliação das obras foi embasada a partir dos seguintes critérios diferenciados pelo Quadro 2:

Quadro 2 - Critérios de aprovação e eliminação do PNLD/Literário

\section{Critérios de} aprovação

1. Qualidade do texto verbal e do texto visual;

2. Adequação de categoria, de tema e de gêneros literários;

3. Projeto gráfico-editorial;

4. Qualidade do material de apoio.

\section{Critérios de eliminação}

1. Qualidade literária da obra (a obra não se caracteriza como didática);

2. Qualidade estética e literária da obra e sua contribuição para a formação do leitor;

3. Isenção de erros crassos e/ou recorrentes de revisão linguística;

4. Isenção de apologia a preconceitos, moralismos e/ou estereótipos que contenham, por exemplo, teor doutrinário, panfletário ou religioso explorados de modo acrítico no texto literário;

5. Correspondência com a categoria declarada no ato da inscrição;

6. Correspondência com o(s) tema(s) declarado(s) no ato da inscrição;

7. Correspondência com o(s) gênero(s) literário(s) declarado(s) no ato da inscrição;

8. Apresentação de prefácio e/ou apresentação que contextualize brevemente autor e obra (esse item não era eliminatório em obras para educação infantil, categorias $1,2 \mathrm{e}$ 3, cf. edital). (GUIA, PNLD/Literário, 2018, p. 14-15).

Fonte: Guia PNLD/Literário (BRASIL, 2018). 
É importante evidenciar que o PNLD/ Literário/2018, direcionado à educação infantil, aos anos iniciais do ensino fundamental (foco da pesquisa) e ao ensino médio, foi considerado transitório, pioneiro $^{2}$, piloto, e teve edital limitado de informações para autores e editoras. Para escola e professores, também houve lacunas, como, por exemplo, no Guia não constavam as resenhas das obras e os critérios avaliativos estão superficialmente apresentados. Outro ponto a ser destacado é que o edital traz exigências baseadas nas recomendações da $3^{a}$ versão da BNCC. No site do programa $^{3}$, na aba PNLD/Literário 2018, são disponibilizados o guia, o passo a passo da escolha e orientações gerais, bem como resultados, informes, manuais e acesso ao sistema de adesão. Já o PNLD/Literário 2020, voltado para o ensino fundamental/anos finais, aborda os direcionamentos com mais clareza nos critérios, para que uma obra possa ser aprovada, baseados na versão final da BNCC, ou seja, as recomendações estão consolidas. $\mathrm{O}$ processo de seleção é um tanto complexo e exige que o professor tenha conhecimento de teoria literária e sobre ilustração e projeto gráfico, o que não costuma comparecer ao curso de Pedagogia, formação obrigatória dos professores de anos iniciais do ensino fundamental.

Conforme afirma Paula (1999, p. 1), "ocorreu uma acentuada profissionaliza- ção na indústria editorial e um enorme crescimento na produção de livros que, na verdade se relaciona com o aumento de seu mercado consumidor", entretanto, o currículo dos cursos de formação de professores não parece ter acompanhado essas transformações. A BNCC enfatiza, ainda, que o ensino de literatura infantil deve considerar o pressuposto de que "o texto é uma prática social, tornando-se a centralidade no processo de formação dos sujeitos" (BRASIL, 2016, p. 92), bem como recomenda, para cada etapa, "um leque de gêneros literários adequados aos leitores em formação" (BRASIL, 2016, p. 96). Nesse sentido, a BNCC não se afasta de documentos oficiais anteriores, como os PCNs, por exemplo, em que a fundamentação teórica dos estudos literários é de base linguística, especificamente, a teoria de gêneros, a partir do que foi entendido da leitura de Mikhail Bakhtin. Isso significa um propósito de aquisição, leitura e mediação afastado de critérios dos estudos literários e unicamente vislumbrado sob um aparato teórico linguístico. Uma seleção de textos literários que não considera estudos do campo específico incorre em equívocos. Visitados os pressupostos do programa, passaremos ao cerne da investigação deste artigo, que é a presença da autoria feminina no PNLD/Literário. 


\section{O lugar da autoria feminina nas obras aprovadas do $\mathrm{PNLD} /$ Literário}

A presente análise traz uma reflexão acerca da autoria feminina nas políticas públicas voltadas para o livro, especificamente o PNLD/Literário, por meio de uma discussão sobre presença de autoras, tendo em vista a relevância das obras e a atualidade das referências. $\mathrm{O}$ Quadro 3 demonstra que a participação feminina é significativa e quase predominante na contemporaneidade no subsistema literatura infantil, o que pode ser observado pelo número de aprovações.

Quadro 3 - Distribuição das obras pelo PNLD/ Literário 2018

\begin{tabular}{|l|r|}
\hline \multicolumn{1}{|c|}{ Obras } & \multicolumn{1}{|c|}{ Total } \\
\hline Inscritas & 1.116 \\
Aprovadas & 704 \\
Reprovadas & 312 \\
Aprovadas para anos iniciais & 334 \\
Aprovadas para educação infantil & 370 \\
Autoria feminina dos anos iniciais & 140 \\
\hline
\end{tabular}

Fonte: elaboração das autoras, 2020.

De modo amplo, foram 1.016 livros inscritos, de diversas editoras, sendo 704 aprovados e 312 reprovados, tendo como base os critérios relatados anteriormente. A partir desses dados, a pesquisa tomou como corpus as obras aprovadas de autoria feminina e voltadas para os anos iniciais, dentre as 334 obras aprovadas.
Retomando o Quadro 2, apontamos que o fato de o foco da pesquisa ser a parte da autoria feminina não anula o destaque de que o critério voltado para a qualidade do texto verbal e do texto visual teve como predominância a representação de ilustração feitas por mulheres. Temos a participação de autoras e ilustradoras circulando no mercado editorial e garantindo a qualidade dos materiais.

Antes de adentrar o universo da representação de autoria feminina nos livros do PNLD/Literário, cabe uma provocação ao percurso apresentado. Se a alfabetização e a leitura das mulheres foram tardias, o que as colocou historicamente como uma espécie de retardatárias no movimento de escrita literária, como explicar a expressiva presença de autoras em publicações direcionadas ao público infantil? Essa relação entre escrita de mulheres e literatura infantil remete ao espaço ocupado pelo feminino na educação das crianças e, por consequência, na formação de leitores. $\mathrm{Na}$ Europa, assim como no Brasil (mesmo que com atraso e algumas peculiaridades significativas), a ascensão da burguesia

[...] demandou um novo sistema de aprendizagem para as crianças [...] que precisam de instrução e conhecimento, a fim de se adestrarem para sociedade que os pais constroem (LAJOLO; ZILBERMAN, 2009, p. 236).

Assim, a literatura infantil "surge" como projeto pedagógico para formação 
das crianças, e a instrução da mulher, uma preparação para a nova função doméstica de preparar as crianças e consolidar a família. A passagem da função de exclusiva cuidadora dos pequenos à de professora e escritora para crianças foi só uma questão de desdobramento dos avanços de espaço conquistados, paralelamente à circunscrição ao aspecto primeiro de mãe e responsável pela infância, em diferentes setores sociais. Desprestigiada academicamente, a formação de leitores, no sentido das ações, da produção e da crítica, tem sido um espaço ocupado pelas mulheres. Dias e Souza (2015, p. 184-185) tratam desse subsistema na cena contemporânea:

Por isso, os campos literários em questão são tão férteis para aprofundarmos as questões relativas às polêmicas contemporâneas ao redor do conceito de cânone: por um lado, a literatura infantil e a juvenil, porque nascidas das intrincadas relações entre pedagogia e mercado - ou seja, no polo oposto ao da legitimação dita propriamente estética - costumam ser marginalizadas do sistema literário geral (oficial, adulto), pois, como apontam Lajolo e Zilberman (1991), é como se a menoridade do público leitor contagiasse todo o subsistema sob o ponto de vista do sistema geral, sendo encarada, por isso, de antemão, como produção cultural inferior - até porque, ao serem definidas por seu destinatário, a literatura infantil e a juvenil sugerem uma produção dependente de demanda, sob medida para o mercado e para a escola e supostamente incompatível com a liberdade criadora e a autonomia estética. Por outro lado, como sistemas autônomos que são, polarizam-se internamente, criando seu próprio cânone acadêmico, que é reconhecido no interior no sistema, mas dificilmente conseguem visibilidade fora dele. Além disso, chama atenção o fato de a produção infantil e juvenil legitimada dentro do próprio sistema (ou seja, consagrada oficialmente segundo critérios acadêmicos), também ter circulação restrita, à semelhança das obras do sistema adulto que são representativas da cultura letrada. Portanto, observar as peculiaridades do funcionamento dos sistemas infantil e juvenil pode ser muito útil para pensarmos o lugar do cânone na cultura e, mais especificamente, no itinerário de leitura das crianças e jovens.

Como já afirmado, "a respeito da produção feminina na Literatura Brasileira, no Período Colonial, nada se tem encontrado nos livros didáticos" (BATISTA, 2012, p. 804); ao passo que, na contemporaneidade, temos desdobramentos do alargamento da produção para crianças, alavancado especialmente após o boom na produção, acontecido na década de 1970. Assim, notamos que a luta pelo lugar nas produções artísticas literárias ainda é progressiva e lenta, mas os resultados são expressivos e marcados na história. O cânone literário de autoria feminina se modifica muito se a mulher retratar vivências resultantes não de reclusão ou repressão, mas, sim, a partir dos resultados que rompem os estereótipos do "feminino" herdados da história e ainda hoje associados à mulher (LOBO, 1992). Tomemos um exemplo: Cecília Meireles é uma autora reconhecida no cânone do sistema geral, enquanto sua produção dedicada à infância é oblitera- 
da por esse mesmo nicho de legitimação. Assim,

[...] a ausência de autoras na parte mais significativa de nossa historiografia literária não se reproduz na historiografia da literatura infantil (SCHMIDT, 1995, p. 67).

O Quadro 4 destaca as principais autoras, tomando como critério de inclusão as que tiveram mais de duas obras aprovadas, as que possuem representatividade na formação de leitores infantis e de professores e as consideradas como renome da literatura desse segmento, pensando que uma das propostas apresentadas pela BNCC seria conciliar a leitura e a cultura canônica com outras formas de expressão literária diversas.

Quadro 4 - Principais autoras das categorias 3, 4 e 5 do PNLD/Literário 2018

\begin{tabular}{|c|c|c|}
\hline Autora & Obra & Quantidade \\
\hline Ana Maria Machado & $\begin{array}{l}\text { O menino que virou escritor } \\
\text { Não se mata na mata lembranças de Rondon } \\
\text { Quero abraço, o que eu faço? } \\
\text { Passarinho me contou } \\
\text { De noite no bosque } \\
\text { De olho nas penas } \\
\text { Histórias africanas } \\
\text { História meio ao contrário }\end{array}$ & 8 \\
\hline Lygia Bojunga & Angélica & 1 \\
\hline Eva Furnari & $\begin{array}{l}\text { Amarílis } \\
\text { Drufd } \\
\text { Marilu } \\
\text { Não confunda }\end{array}$ & 4 \\
\hline Marina Colasanti & $\begin{array}{l}\text { Cada bicho com seu capricho } \\
\text { Doze reis e a moça no labirinto do vento } \\
\text { A moça tecelã }\end{array}$ & 3 \\
\hline Roseane Murray & $\begin{array}{l}\text { Brinquedos e brincadeiras } \\
\text { Duas casas } \\
\text { Jardins } \\
\text { Retratos }\end{array}$ & 4 \\
\hline Silvia Orthof & $\begin{array}{l}\text { Catarina e o lagarto } \\
\text { A viagem de um barquinho } \\
\text { Chora não! }\end{array}$ & 3 \\
\hline Cecilia Meireles & Ou isto ou aquilo & 1 \\
\hline Cora Coralina & As cocadas & 1 \\
\hline Anna Claudia Ramos & $\begin{array}{l}\text { Carteiro tem nome? } \\
\text { Hoje é amanhã? }\end{array}$ & 2 \\
\hline Nye Ribeiro & $\begin{array}{l}\text { De bem com a vida } \\
\text { Lorotas e fofocas } \\
\text { Macaquice }\end{array}$ & 3 \\
\hline Tatiana Belenky & $\begin{array}{l}\text { Diversidade } \\
\text { O caso do bolinho }\end{array}$ & 2 \\
\hline
\end{tabular}

Fonte: elaboração das autoras, 2020. 
No Quadro 5, fica evidente a preferência por Ana Maria Machado no rol das produções infantis, e, consequentemente, a seleção confirma que sua obra tem maior circulação entre o público infantil, uma vez que a distribuição pela política pública acontecerá de modo gratuito. Dona de uma vasta produção, Ana Maria Machado escreveu textos que se situam desde um lugar de densidade literária até escritos mais simples, ligados a claros projetos pedagógicos. A lista reproduz, em quantidade e variedade, algumas considerações sobre a produção da autora, ou seja, é alguém que mais produziu escritos para crianças desde os anos 1970, alcançou legitimação dentro do subsistema, no Brasil e no exterior, e sua visibilidade, por consequência, é grande. A seleção desse PNLD/Literário apresenta uma gama de caminhos seguidos pela autora: duas biografias $(O$ menino que virou escritor e Não se mata na mata: lembranças de Rondon); uma tradução (Quero abraço, o que eu faço?); clássicos premiados (De olho nas penas; Passarinho me contou e História meio ao contrário); recontos africanos (Histórias africanas). Ou seja, o PNLD/Literário reproduz um quadro de referências de certo modo previsível, uma vez que a autora em questão tem grande reconhecimento pela qualidade de algumas obras e também pelo volume de produção. É como apostar em um nome em que quase sempre é possível acertar: se, por um lado, é uma boa aposta, por outro, deixamos de trazer à leitura outras autoras, ausentes ou pouco representadas, como Adriana Falcão, Ângela Lago e Rosa Amanda Strauzs, para citar poucos exemplos, o que significa ainda reproduzir certa supremacia de determinados nomes em detrimento de outros. A busca por muitos títulos da autora parece ser muito mais um problema de repertório de quem seleciona do que da autora mesmo. Concordamos, nesse sentido, com Dias e Souza (2015, p. 186):

Dona de uma vasta obra, que conta com mais de cem livros, Ana Maria Machado é um nome muito familiar quando o assunto é literatura infantil. Nome de prestígio, já recebeu inúmeros prêmios por suas obras, além do mais renomado da categoria - o Hans Christian - e da cadeira na Academia Brasileira de Letras. Sua produção, muito próxima das expectativas escolares - o que pode ser percebido pela construção de textos que trabalham ludicamente com a linguagem e colocam a criança no centro da narrativa, muitas vezes encaminhada para discussões de cunho ideológico -, tornou-se uma espécie de selo da produção literária dirigida às crianças no Brasil.

Portanto, não queremos questionar a qualidade literária dos títulos de Ana Maria Machado. Autora de romances e livros de poesia, ganhadora do Prêmio Hans Christian Andersen, ela é também uma militante da causa da leitura no país, além de ensaísta, tradutora e palestrante. Isso significa muito em relação à ocupação de um espaço de atuação na formação de leitores. Conforme Bastos (1995, p. 17): "Ana jamais tolerou a mesmice, a escritora gosta de driblar as fórmulas, sua obra é um marco de renovação da linguagem na literatura infantil brasileira", e "suas 
narrativas respeitam a inteligência e a sensibilidade infantis. Ana experimenta formas e temáticas diversas, brinca com as palavras e induz à reflexão sem pedagogismos". No que tange à sua própria trajetória, Machado (1996, p. 44) afirma:

Ser leitora e escritora é uma escolha ligada ao intenso prazer intelectual que essas atividades me dão. Escrevo porque gosto da língua portuguesa, gosto de histórias e conversas, gosto de gente com opiniões e experiências diferentes, gosto de outras vidas, outras ideias, outras emoções, gosto de pesar e de imaginar. Em todo esse processo, a leitura foi fundamental.

A pesquisadora e escritora Anna Cláudia Ramos (2006, p. 17) complementa que Ana Maria Machado é uma grande pensadora sobre a leitura e o fazer literário, "seus ensaios abordam aspectos fundamentais sobre a democratização da leitura de literatura em nosso país e sobre os processos de criação", e que o faz através de uma "escrita leve e acessível, quase um bate-papo com o leitor". Em uma entrevista, em 2001, foi questionado: que títulos não podem faltar na biblioteca da escola? E a escritora respondeu o seguinte:

Ana Maria: Pergunta difícil essa. Prefiro citar autores: Monteiro Lobato, Ruth Rocha, Ziraldo, Sylvia Orthof, Bartolomeu Campos Queiroz, Marina Colasanti, Pedro Bandeira, João Carlos Marinho, Mary e Eliardo França, Ricardo Azevedo, Marcos Rey, José Paulo Paes, Cristina Porto, além das duas autoras brasileiras que receberam o Prêmio Christian Andersen, a Lygia Bojunga e eu (RAMALHO, 2001, não paginado).
Das sete escritoras citadas pela autora, cinco se fazem presentes na lista como parte das produções aprovadas pelo PNLD/Literário, ou seja, na entrevista com Ana Maria Machado, entrevemos um painel de referências que coloca nossa autora também no espaço de crítica literária desse subsistema. Entretanto, se levarmos em consideração que a entrevista se deu no início dos anos 2000, percebemos que a seleção do PNLD/Literário reproduz uma prática muito criticada na seleção dos textos que compõem os livros didáticos do ensino médio, que é a falta de repertório mais contemporâneo. Os autores citados pela entrevistada são nomes consolidados da escrita para crianças e jovens, em sua maioria, desde a década de 1970. Portanto, a reprodução de certos nomes parece denunciar ainda a ausência de pesquisa sobre literatura infantil contemporânea.

Eva Furnari e Tatyana Belinky também são nomes representativos de obras importantes na história da literatura infantil brasileira. Eva Furnari tem sua carreira dividida em duas frentes, a de escritora e a de ilustradora. Sua obra foi agraciada com diversos prêmios, entre eles, sete Prêmios Jabuti, da Câmara Brasileira do Livro, alguns prêmios da Fundação Nacional do Livro Infantil e Juvenil (FNLIJ), Prêmio da Associação Paulista de Crítica (APCA) pelo conjunto da obra, autoria e ilustração. Tatiana Belinky (1919-2013) foi uma escritora 
de literatura infanto-juvenil, roteirista e tradutora de grandes obras russas e responsável pela primeira adaptação para a televisão de $O$ Sítio do Pica-pau Amarelo. Em 1994, Tatiana Belinky recebeu importantes prêmios, como o Prêmio Jabuti, com o livro A Saga de Siegfried, e o Prêmio Fundação Nacional do Livro Infantil e Juvenil, na categoria poesia, com o livro Um caldeirão de poemas; em 2009, foi eleita para a cadeira no 25 da Academia Paulista de Letras. Tratam-se, portanto, de autoras cujas escritas (em texto e imagem, no caso de Furnari) têm reconhecimento de instâncias legitimadoras do subsistema literatura infantil e já se tornaram nomes consagrados no universo brasileiro, além de serem legítimas representantes de nossa cultura letrada também fora do Brasil. A presença das duas, no número de ocorrências, parece ser bastante razoável, especialmente se pensarmos que ambas trazem peculiaridades muito afeitas à produção para crianças, a escrita poética e o diálogo criativo entre palavra e imagem.

Marina Colasanti também é nome importante no rol de autoras de literatura infantil e juvenil. Como Ana Maria Machado, Colasanti também escreve poemas e ensaios e é tradutora de livros infantis e juvenis, além disso, muitas de suas obras giram em torno de personagens femininas. De acordo com Silva (2007, p. 32-40):
Marina Colasanti sempre esteve preocupada com a discussão da condição feminina, seja no discurso literário, através de suas personagens femininas, na prosa, ou da voz lírica, nos versos; seja no discurso jornalístico.

A autora não esconde esse projeto de fazer valer seu lugar de mulher em um universo em que os homens parecem querer reservar concessão às vozes femininas, nas palavras da escritora:

A questão da mulher sempre foi muito importante para mim. É difícil entender uma mulher que se queira intelectual, que trabalhe no campo das letras e que não faça reflexões sobre a sua própria condição no mundo. No entanto, isso existe. Mas, para mim, seria impossível. É o processo natural, se eu estou refletindo sobre o porquê das coisas, a primeira reflexão que se impõe é por que eu, nós, mulheres, somos cidadãs de segunda categoria, ou éramos, ou ainda somos?! (COLASANTI apud SILVA, 2007, p. 33).

Em relação aos títulos de Colasanti, entretanto, podemos perceber uma redundância, que é a presença de $A$ moça tecelã, conto presente em Doze reis e a moça no labirinto do vento. A moça tecelã , publicado como livro independente, é resultado do grande sucesso do conto, que percorreu muitos livros didáticos $\mathrm{e}$ terminou por ganhar vida própria nesse volume. Outras obras de Colasanti poderiam ter sido contempladas para evitar a repetição do texto, como, por exemplo, Uma ideia toda azul ou Longe como o meu querer, que caminham no mesmo sentido de contos maravilhosos como Doze reis e a moça no labirinto do vento. 
Roseana Murray, Anna Claudia Ramos e Nye Ribeiro, especialmente esta última, são presenças que fogem um pouco à previsibilidade da presença das outras já citadas, que pertencem ao que podemos chamar de cânone da literatura infantil brasileira. As duas primeiras atuam junto a professores como palestrantes e já alcançam grande número de publicações. São, portanto, de certa forma, acertos na aposta de diversificar o universo de acervo que possivelmente muitas bibliotecas escolares já possuem. Entretanto, as obras escolhidas caminham no mesmo sentido de construção bem-humorada e jogos de linguagem, recursos muito frequentes, e até desejáveis, na produção para crianças. A presença constante da brincadeira e do lúdico marca, porém, certa ausência, explicada pela presença única de texto de Lygia Bojunga.

Não surpreende a presença ínfima, na lista do PNLD/Literário, de Lygia Bojunga. A autora traz à representação literária obras que encenam os agudos da existência humana, nem sempre com finais conciliatórios, em relação à dor que ganha espaço na narrativa. Angélica, assim como $O$ sofá estampado, é um livro da autora que circula mais no universo escolar pelo caráter fabulesco da ficção, que põe sob véu de alegoria as angústias humanas e os descompassos sociais que denuncia. $\mathrm{O}$ silêncio em relação à pouca presença de títulos de Lygia Bojunga, primeira autora brasileira a receber o Prêmio Hans Christian Andersen, diz respeito a um desconforto dos mediadores em lidar com temas complexos, considerados tabus em espaços de escolarização, e ainda a um entendimento de que a literatura infantil deve cumprir um papel de apaziguamento das angústias infantis.

A infantilização da literatura infantil reaproxima a produção de um caráter pedagógico do qual se originou. O caráter estético do fazer literário não pode ser subtraído em detrimento de uma proposta pacificadora de conflitos, conforme argumenta María Teresa Andruetto (2017, p. 15), autora e ensaísta argentina, diante da premissa de que a literatura infantil também é literatura: "Para que isso seja verdade, deve-se evitar com toda força ações, estereótipos e retóricas que tanto povoam livros infantis: escritas servis disfarçadas com novas roupagens". A escola, como espaço quase exclusivo de formação de leitores em nosso país, não pode subestimar a criança e retirar dela o direito a experiências de leitura mais complexas, conforme acrescenta Andruetto (2017, p. 29):

No ato de ler, um livro se recolhe de sua condição de objeto que tem dono para se converter num ser vivo, capaz de nos interrogar, de nos perturbar e de nos ensinar a olhar zonas ainda não compreendidas de nós mesmos. Nessa diversidade de experiências, nessa multiplicidade de sentidos na qual os livros os submergem, está sua riqueza e a possibilidade de mergulho em nossas zonas indômitas. 
No recorte feito para este artigo, podemos perceber que a presença maior de algumas autoras se dá pelo fato de que atuam em diferentes frentes da formação de leitores, imprimindo em suas carreiras espaços de ação que se constituem como alavancadores de sua produção e da própria leitura no país. Marina Colasanti e Ana Maria Machado, por exemplo, realizam palestras e traduzem textos ficcionais e ensaísticos relacionados à leitura literária. Entretanto, não podemos ignorar que, se hoje essas autoras recebem prêmios, títulos, cadeiras na Academia Brasileira de Letras, isso é devido a árduas lutas de suas antecessoras, visto que, até a década de 1970, de acordo com Schmidt (1995), somente Rachel de Queiroz, Cecília Meireles e Clarice Lispector haviam sido reconhecidas pela crítica acadêmica. $\mathrm{O}$ perfil das autoras e de suas produções representam muito para o capital cultural de nossa literatura.

\section{Reflexões finais}

A partir dos critérios de seleção das obras literárias para o PNLD/Literário e também das normas estabelecidas para o funcionamento do programa, procuramos tecer algumas reflexões acerca do lugar da autoria feminina no subsistema da literatura infantil. Se, por um lado, a presença da literatura na BNCC e, consequentemente, no programa norteado por ela tem fundamentação teórica mais ligada à Linguística e a um uso mais estrutural e pragmático da língua, a presença das mulheres como autoras é bastante expressiva e reúne títulos de qualidade literária reconhecida.

As análises provisórias apresentadas trazem uma pauta de mão dupla sobre a presença da autoria feminina no PNLD/Literário, no que diz respeito aos avanços em relação à visibilidade das mulheres, mas também à reprodução de certos padrões instituídos pela tradição legitimadora da cultura letrada, afinal, autoras consagradas, como Ana Maria Machado, por exemplo, ocupam mais espaço que outras cujos nomes ou premiações ainda não lhes conferem espaço em seleções de larga escala. A necessidade de um trabalho crítico mais atualizado sempre foi um fator de dificuldade da literatura infantil brasileira, devido ao preconceito acadêmico em relação a esse subsistema, mas algumas pesquisas têm avançado e é importante não destituir as autoras já canônicas, mas ampliar o rol de referências.

Por esse viés, considerando o quão lucrativo é o mercado editorial e associando tal fato ao sistema capitalista que determina as condições de produção do livro didático, é significante ressaltar que algumas pesquisas relatam constantes escolhas tendenciosas e olhares já fixos em determinados nomes. Em relação ao sistema literário geral, a 
autoria feminina tem maior visibilidade no subsistema infantil, mas, dentro do próprio campo, ainda reproduz certos vícios do sistema maior, e isso não é uma questão de autoria, mas de trabalho crítico, que deveria estar no bojo de qualquer seleção para compra em larga escala, por uma questão de responsabilidade com o erário público e também de acolhida à já subtraída autonomia docente.

\section{Children's literature in} action: the marks of female authorship in works approved by the PNLD/Literary

\section{Abstract}

The place of women in societies has never been more in evidence than in this century, although the discussions have not yet inaugurated now. The present work makes an analysis of the representativeness of female authorship in public policies focused on the literary book, especially around the books approved by the National Plan for Literary Materials and Didactic Book (PNLD), from the 2018 edict. In effect, we weave a dialogue between children's literature, the presence and legitimacy of female authorship, in a historiography with marks of symbolic play and gender forces. We outlined a path that sought both to quantify the works of female authors and to problematize the PNLD's evaluation criteria and the recurrence and predominance of some works. Thus, we note that the struggle for place in literary artistic productions is still progressive and slow, but the results are expressive and marked in history.

Keywords: Children's literature. Women's authorship. PNLD. Literary book.

\section{Notas}

1 A partir do conceito de sistema literário, de Antonio Candido, Dias e Souza $(2015,182)$ trazem o de subsistemas, infantil e juvenil, para circunscrever a produção dirigida a crianças e jovens, entendendo a peculiaridade dos campos e sobretudo a inter-relação entre eles: "Segundo Antonio Candido (2006), não se pode falar em sistema literário sem a continuidade e regularidade de produção e recepção proporcionada por um grupo de autores autoconscientes de seu papel; um público que reconheça socialmente a atividade dos primeiros e sem os quais a obra produzida não vive; um mecanismo transmissor, que viabiliza materialmente a circulação da obra; e um sistema de valor que dê sentido aos três movimentos (produção, recepção e circulação)".

2 Anteriormente, os livros literários tinham como critérios os estabelecidos pelo PNBE, como qualidade do texto, relação cultural e projeto gráfico editorial.

3 Disponível em: https://www.fnde.gov.br/index.php/ programas/programas-do-livro/pnld.

\section{Referências}

ANDRUETTO, M. T. A leitura: outra revolução. São Paulo: SESC SP, 2017.

BASTOS, Dau (org.). Ana \& Ruth: vinte e cinco anos de literatura. Textos de Carlos Moraes e Marisa Lajolo. Rio de Janeiro: Salamandra, 1995.

BATISTA, E. R. A produção literária feminina. In: SEMINÁRIO NACIONAL MULHER E LITERATURA, 14; SEMINÁRIO INTERNACIONAL MULHER E LITERATURA, 5. Anais [...]. Brasília: Universidade de Brasília, 2011. p. 801-811. 
BOURDIEU, P. A economia das trocas simbólicas. Tradução Sergio Miceli et al. 6. ed. São Paulo: Perspectiva, 2007.

BRASIL. Ministério da Educação. Base Nacional Comum Curricular. Brasília, DF: MEC, 2016.

BRASIL. Guia do Plano Nacional de Livro e Material Didático (PNLD) literário. Brasília, DF, 2018.

DIAS, A. C. P.; SOUZA, R. C. de S. O lugar do(s) cânone(s) na formação dos sistemas literários infantil e juvenil brasileiros. Elos: Revista de Literatura Infantil e Juvenil, Santiago de Compostela, n. 2, p. 181-201, 2015.

FREITAG, B.; MOTTA, V. R.; COSTA, W. F. O livro didático em questão. 3. ed. São Paulo: Cortez, 1997.

LEAL, V. M. V. O feminismo com agente de mudanças no campo literário brasileiro. In: STEVENS, C. (org.). Mulher e literatura 25 anos: raízes e rumos. Florianópolis: Mulheres, 2010. p. 183-207.

LOBO, Luiza. A dimensão histórica do feminismo atual. In: RAMALHO, Cristina (org.). Literatura e feminismo: propostas teóricas e reflexões críticas. Rio de Janeiro: Elo, 1992. p. 41-50.

MACHADO, Ana Maria. Esta força estranha: trajetória de uma autora. São Paulo: Atual, 1996.

MUNAKATA, K. Produzindo livros didáticos e paradidáticos. 1997. Tese (Doutorado em História e Filosofia da Educação) - Programa de Estudos Pós-Graduados em Educação: História, Política, Sociedade, Pontifícia Universidade Católica de São Paulo, São Paulo, 1997.

PAULA, R. de. A política de seleção e distribuição dos livros didáticos de história no estado de São Paulo. São Paulo: Anped, 1999. (UNESP - Ar.).

RAMALHO, Priscila. A literatura deve dar prazer. Revista Nova Escola, Fala, mestre!, edição 145, set. 2001.
RAMOS, Anna Claudia. Nos bastidores do imaginário: criação e literatura infantil e juvenil. São Paulo: DCL, 2006.

SCHMIDT, Rita Teresinha. Repensando a cultura, a literatura e o espaço da autoria feminina. In: NAVARRO, Márcia Hoppe (org.). Rompendo o silêncio: gênero e literatura na América Latina. Porto Alegre: Editora da UFRGS, 1995.

SILVA, S. A. B. C. De mulheres e símbolos: figuras do feminino no bildungsroman Ana Z., aonde vai você? Temporis (ação), Goiás, UEG, v. 1, n. 9, p. 32-40, jan./dez. 2007. XAVIER, Elódia. A hora e a vez da autoria feminina: de Clarice Lispector a Lya Luft. In: DUARTE, Constância Lima; DUARTE, Eduardo de Assis; BEZERRA, Kátia da Costa (org.). Gênero e representação na Literatura Brasileira. Belo Horizonte: UFMG, 2002. p. 157-166.

LAJOLO, M.; ZILBERMAN, R. A formação da leitura no Brasil. São Paulo: Global, 2009.

WOOLF, V. Um teto todo seu. São Paulo: Nova Fronteira, 1985. 